\title{
COMUNICAÇÃO E CULTURA NO PROCESSO DE SOCIALIZAÇÃO
}

\author{
Aníbal Alves \\ Universidade do Minho
}

\section{INTRODUÇÃO: SOCIEDADE, ANOMIA E SOCIALIZAÇÃO}

Todos os dias saltam aos nossos olhos na Imprensa e em outros meios de Informação de Actualidade inúmeros casos de escândalo, de fraude, de crime, de atentados, enfim, de um grande conjunto de acções e de atitudes contrárias à convivência social. $\mathrm{Na}$ experiência colectiva internacional paira, de modo contínuo, um clima de ameaça, no terrorismo, nas guerras fratricidas, invasoras, espoliadoras.

Face a esta crescente pressão de medo e de anomia destruidores impõe-se a todos nós uma imperativa questão: que fazer e como fazer? Revejo na pergunta a mesma interrogação, formulada em tempos ainda recentes pelo sociólogo francês Alain Touraine (1997) no seu livro Pourrons-nous vivre ensemble? (Poderemos nós viver juntos?).

Sabemos que as Sociedades Humanas sempre procuraram garantir a sua constituição e existência duradoura, por meio daquele conjunto de ideias, valores, normas e comportamentos comuns a que se chama cultura. É esta que, aprendida, partilhada e transmitida, torna possível a vida em sociedade e permite a ela e aos seus membros a realização de seus fins. É pela cultura que a sociedade se constitui, vive e perdura em sucessivas gerações. Desde que, como insistia a resposta positiva de Alain Touraine, a própria sociedade promova e assegure continuadamente o processo de socialização.

É a este processo que dedico a presente reflexão. Porquê? Pela sua íntima conexão com a temática da comunicação, centro dos meus e nossos estudos, e da comunicação social que, naquele processo, ganha particular e próprio sentido. Encontrei com agrado esta perspectiva especialmente sublinhada por E. Rosengren (2000) no seu livro Communication, que retomo na presente refle- 
xão. Com efeito, considero a abordagem muito pertinente para o nosso Encontro. Entendo que no processo de socialização se encontram implicadas, de forma ímpar, a cultura e a comunicação, que constituem o objecto destes nossos II Encontros Luso-Galegos de Comunicación e Cultura.

Procurarei mostrá-lo através de duas perspectivas complementares: a primeira, numa visão da cultura como sub-sistema estruturante do Sistema Social Global; a segunda, numa perspectiva de construção/reconstrução permanente da sociedade, através do processo de socialização. Em ambas as perspectivas, permanece o mesmo objectivo: sublinhar a natureza e relevância sociais da comunicação e tomá-las em consequente e devida consideração na nossa Disciplina - a Área de Estudos da Comunicação.

\section{CULTURA E COMUNICAÇÃO}

\subsection{A sociedade global como um sistema de sistemas}

Para o presente propósito vamos considerar que uma sociedade humana se estrutura, se desenvolve e se mantém, graças a uma tríplice dimensão: cultural, social e material. Pensando a sociedade no seu todo como um sistema - o sistema social global - aquelas dimensões correspondem aos três sub-sistemas seguintes:

- sistema cultural de ideias e valores;

- sistema social de acções e interacções;

- sistema material de obras ou artefactos.

$\mathrm{Na}$ realidade social, os três sistemas estão implicados uns nos outros, de tal modo que as acções, como as obras delas resultantes, são inseparáveis das correspondentes ideias e valores. No entanto e por mais difícil que seja identificar em concreto a parte de cada sistema, a distinção é importante para a adequada compreensão das formas de organização e de acção características de cada sociedade, em sua situação e evolução históricas. Sendo as três dimensões essenciais e interdependentes, qualquer sociedade poderia ser descrita na perspectiva de uma ou de outra. Todavia, para o nosso propósito consideramos o sistema cultural no centro da organização e do processo sociais. Mais propriamente queremos pôr em destaque o sistema dos valores sociais. 


\subsection{Os valores estruturantes da sociedade}

Para pôr em relevo o lugar e função dos valores na estrutura e na dinâmica da sociedade vamos recorrer à figura usada por Karl Rosengren (2000) no seu já referido livro Communication, e já antes publicada na obra de sua coordenação e autoria, Media, Effects and Beyond (Rosengren, 1994).

A «Grande Roda da Cultura» (ver figura) pretende expressar como a sociedade se organiza e age, no seu todo como nas suas partes, a partir de valores básicos e para valores básicos. Trata-se naturalmente de um modelo simplificador mas que visa representar fundadamente a realidade social. Três aspectos principais merecem destaque, como se detalha nas alíneas seguintes.

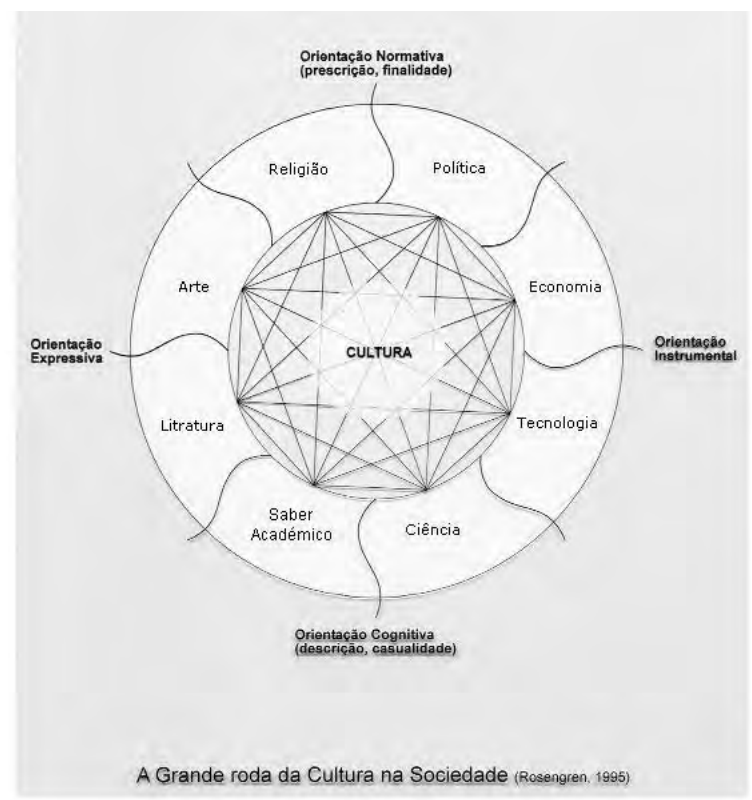




\subsubsection{Os Valores Básicos}

Numa perspectiva geral, que a história ilustra, qualquer sociedade se constitui e age sob a orientação de alguns valores básicos, tais como o bem, a verdade, a beleza, a justiça, ou seus equivalentes. Podemos associá-los nos dois pares de orientação de valor seguintes:

- orientação cognitiva em oposição a orientação normativa;

- orientação expressiva em oposição a orientação instrumental.

Estes quatro pólos de orientação de valor, inscritos na figura, enquadram, em cima e em baixo, à esquerda e à direita, a Grande Roda da Cultura. Sob a orientação destes valores se constituem as instituições sociais básicas e seus quadros de acção. As oito categorias inscritas no espaço do círculo externo representam uma tipologia possível. As instituições estão espacialmente situadas, de modo a expressar, por um lado, a sua ligação à orientação de um valor básico, e, por outro, a sua maior proximidade com outras instituições. Por exemplo, a orientação cognitiva, da ordem da descrição ou da causalidade, abrange e relaciona as Instituições do Saber Académico e da Ciência. Mas é também visível a ligação desta última com as Instituições da Tecnologia. De modo semelhante, a Religião e a Política partilham, em contiguidade, a orientação normativa dos fins e das leis. Todas as linhas de divisão e de articulação das Instituições são derivadas a partir do círculo interior, o eixo motor da roda inteira, a cultura.

\subsubsection{O sistema de acção social}

O círculo médio da figura representa o sistema da acção social. Ele abrange a acção, a interacção e as relações que as Instituições sociais desenvolvem entre si. A imagem de rede resultante dos vectores assinalados tornar-se-ia demasiado densa e até ilegível se pretendêssemos incluir a representação das relações e interdependências entre níveis institucionais mais específicos. Imagine-se, por exemplo, a quantidade e complexidade de acções e interacções de uma municipalidade, de uma escola, de um par- 
tido político, de uma organização internacional, de um estado. O importante é notar que as Instituições, através dos seus sistemas de acção e dos sistemas de artefactos dela resultantes, se ligam e afectam mutuamente através de uma infinidade de relações e interacções.

\subsubsection{A dinâmica do sistema cultural}

Os seus três círculos concêntricos correspondem aos três sistemas das ideias, das acções e dos artefactos. Ao centro, como que no eixo da roda, está a cultura, enquanto princípio de toda a acção social.

Notámos já que na figura se expressa em apenas um vector, o conjunto de relações e interacções entre cada par de instituições. Mas na malha formada por estes poucos vectores se simboliza a imensa rede de cruzamentos e de interdependências em que se realizam as diferentes actividades sociais por acção de seus respectivos agentes. Por aí se adivinha a amplitude e intensidade do real trabalho de estimulação, articulação e regulação levado a cabo pela cultura. Ora, qual a natureza ou modalidade de tamanho trabalho? Vendo bem, podemos identificá-lo com um trabalho próprio da comunicação. Trata-se, na verdade e em profundo sentido, da radical acção comunicacional, para usar a expressão cunhada pelo filósofo Jurgen Habermas.

A esta perspectiva de ordem sistémica, importa juntar uma outra, não menos marcada pelo seu carácter comunicativo. Trata-se da transmissão da cultura aos membros da sociedade e, particularmente, aos novos membros e às novas gerações. A esta tarefa complexa chamaram os sociólogos e demais cientistas sociais o processo de socialização. É a natureza comunicativa deste processo que vamos pôr em relevo no ponto seguinte.

3 O PROCESSO DE SOCIALIZAÇÃO E SUA DIMENSÃO COMUNICATIVA

\subsection{Socialização e comunicação}

Por socialização entende-se o processo pelo qual os indivíduos humanos se tornam membros da sociedade. Costumam distinguir-se dois modos de socialização principais: a socialização pri- 
mária, que leva um indivíduo no sentido biológico a ser integrado numa dada sociedade; socialização secundária, que concerne às dimensões de assimilação e adaptação permanentes dos membros da sociedade ao longo da sua vida. Também se pode incluir no conceito de socialização a transmissão e assimilação da cultura entre as sucessivas gerações. Trata-se sempre da integração dos indivíduos na estrutura social através da interiorização das ideias, valores, normas e códigos simbólicos ou cultura.

Posto que a socialização implica o desenvolvimento do indivíduo também se pode designar processo de individuação ou de personalização; considerando, por outro lado, que ela consiste na assimilação da cultura, pode igualmente designar-se por enculturação. Mas em todas as três dimensões do processo aparece claramente a relevância da comunicação. Assim o destacou por exemplo o antropólogo Ralph Linton (1945) na sua definição de cultura: «uma cultura é a configuração de comportamento aprendido e resultados de comportamento cujos elementos componentes são partilhados e transmitidos pelos membros de uma sociedade particular».

\subsection{Os agentes da socialização}

Se repararmos na tipologia das instituições da Grande Roda dos Valores, não encontramos nela nenhuma categoria explícita destinada a assegurar o decisivo processo de socialização. Qual será a razão? É que tratando-se de tarefa comum ao conjunto da sociedade não podia ela ser confinada apenas a um único corpo institucional de acção. Mas não podia por outro lado ficar tão importante função dependente do puro jogo interactivo das instituições sociais especializadas. Por isso a sociedade exige a um conjunto de agentes sociais concretos, independentemente da sua pertença institucional, que assegurem propositadamente o referido processo de socialização.

Com E. Rosengren, distinguimos oito principais agentes de socialização, a seguir indicados:

Agentes que se encontram em todas as sociedades, incluindo as menos diferenciadas: 
- Família;

- Grupo de Pares;

- Grupo de Trabalho.

Agentes característicos das sociedades mais complexas:

- Sacerdotes (com suas igrejas);

- Professores (com suas escolas);

- Agentes da lei (com suas organizações judiciais e policiais).

Agentes mais característicos das sociedades modernas:

- Grandes movimentos sociais (incluindo a sua organização mais ou menos formalizada a nível local, nacional internacional);

- Os meios de comunicação ou media (desde os mais gerais até aos mais especializados, desde a carta circular e boletim de informação até aos grandes meios de comunicação de massa).

Estes agentes organizam-se e agem de modos muito diferenciados. Mas todos desenvolvem intensa actividade na organização, actualização e partilha da cultura existente nos diferentes níveis e partes da sociedade, e transmitida de geração em geração. Nessas e similares formas de acção, o seu principal instrumento é a comunicação. Esta revela-se, assim, como o modo próprio da socialização, pela qual a cultura se actualiza em novos e renovados membros e a sociedade se constrói e reconstrói. É também aqui e de modo especial, a comunicação a fazer andar a roda da cultura, isto é, a roda das ideias e dos valores.

3.3 Uma dupla perspectiva da comunicação social

3.3.1 A teia social das trocas comunicativas

Para ilustrar a multiplicidade e intensidade da comunicação no seio da vida e acção sociais recorremos a uma representação gráfica das trocas comunicativas entre entidades sociais de diferentes níveis de organização.

Como se vê na tabela 1, limitamo-nos às seguintes entidades: indivíduo, grupo, organização, comunidade, sociedade. A comuni- 
cação intra-nível está assinalada por «0» e a de inter-nível por «X» ou «y», no caso, respectivamente, de emissão ou de recepção.

Tabela 1: Comunicação intra e inter entidades sociais

\begin{tabular}{|l|c|c|c|c|c|}
\hline De $\backslash$ Para & Indivíduo & Grupo & Organização & Comunidade & Sociedade \\
\hline INDIVIDUO & 0 & $\mathrm{y}$ & $\mathrm{y}$ & $\mathrm{y}$ & $\mathrm{y}$ \\
\hline GRUPO & $\mathrm{x}$ & 0 & $\mathrm{y}$ & $\mathrm{y}$ & $\mathrm{y}$ \\
\hline ORGANIZAÇÃo & $\mathrm{x}$ & $\mathrm{x}$ & 0 & $\mathrm{y}$ & $\mathrm{y}$ \\
\hline COMUNIDADE & $\mathrm{x}$ & $\mathrm{x}$ & $\mathrm{x}$ & 0 & $\mathrm{y}$ \\
\hline SOCIEDADE & $\mathrm{x}$ & $\mathrm{x}$ & $\mathrm{x}$ & $\mathrm{x}$ & 0 \\
\hline
\end{tabular}

Mesmo reduzida a estas entidades sociais podemos perspectivar a densa teia social que a inter-comunicação continuamente realiza. É certo que esta inter-comunicação envolve, naturalmente, o comportamento humano em toda a sua complexidade bio-psico-socio-cultural. Mas é por esta última e pela ordem significativa que instaura, que a comunicação se torna meio de acção e de regulação sociais.

\subsubsection{Os grandes meios de comunicação social (Media)}

Nas sociedades actuais ganharam extraordinária visibilidade e importância os grandes meios de comunicação social e as novas tecnologias de comunicação. Uns e outras aumentaram grandemente as capacidades e potencialidades das instituições de comunicação mediática, e, também, as capacidades de comunicação das pessoas e dos públicos quer enquanto emissores, quer enquanto receptores. Estas últimas, particularmente, poderão favorecer maior actuação pessoal do público no palco da comunicação social, como espaço de contínua formulação e reformulação de ideias, valores e comportamentos. 


\section{CONSEQUÊNCIAS PARA A ÁREA DE ESTUDOS \\ DA COMUNICAÇÃO}

Das reflexões anteriores sobre as relações e implicações da comunicação com a cultura, e, designadamente, na comunicação mediática, gostaria de retirar dois tipos de consequências para a área de estudos da comunicação. Um relacionado com a formação académica, outro com a agenda da investigação científica, dois aspectos de manifesta pertinência na temática do nosso Encontro.

\subsection{O conhecimento social na formação em comunicação}

A centralidade da comunicação, ao nível da visão sistémica como ao nível da visão processual do sistema social global, não permite dúvidas sobre a própria natureza social da comunicação.

Daí que o conhecimento da comunicação seja ele próprio indissociável do conhecimento da realidade social. A formação para a comunicação há-de pois incluir o estudo das teorias dos métodos adequados para um conhecimento substantivo da estrutura e dinâmica gerais das sociedades, bem como das suas instituições e campos de acção básicos. Com efeito, o especialista em comunicação, concebida necessariamente também como dimensão interactiva da sociedade, não a poderá entender se desconhecer a natureza e características próprias da mesma sociedade. Por isso os programas de formação deverão incluir algumas disciplinas de ciências sociais tais como sociologia, antropologia, psicologia (social), economia, direito, história e geografia. Não se advoga uma sobrecarga do estudante com programas extensivos sobre o conhecimento sociológico. Mas afirma-se que a sua perspectiva é indispensável, não só para a formação básica do especialista, mas também porque as ferramentas de ordem teórica e metodológica das ciências sociais lhe fornecerão mais adequada habilitação para tratar as questões de comunicação com que se defrontará na vida profissional.

É minha convicção que esta dimensão curricular, sem prejuízo das diferentes modalidades e das circunstâncias da formação, é conjugável com as outras componentes também indispensáveis 
para o perfil académico desejado. Muitos cursos instituídos no ensino superior que conheço contemplam aquela dimensão. Mas outros há que a ignoram, limitando-se ao saber cognitivo e operacional estritamente requeridos pelo domínio prático de alguns processos e técnicas de comunicação e/ou de informação. A formação universitária no campo da comunicação social ou das ciências da comunicação, tendo até em consideração os desideratos da Declaração de Bolonha, parece-me não poder prescindir, sem lacuna grave, da perspectiva das ciências sociais nos programas de formação.

\subsection{Comunicação e socialização na agenda científica}

A investigação em comunicação, designadamente no que se refere aos media e sua alegada influência social, teve grande desenvolvimento ao longo da sua história. Um vasto conjunto de pesquisas de grande impacto, principalmente nos Estados Unidos, mas também na Europa e em outras regiões, contribuiu fortemente para criar uma imagem positiva da área de estudos da comunicação. Ainda jovem, a disciplina tem-se imposto com manifesto crescimento, através de processos muito diferentes e com programas largamente heteróclitos. Será certamente pela investigação científica, que melhor prosseguirá a busca da sua própria identidade e do reconhecimento institucional. O que aqui pretendemos sugerir é mais da ordem da perspectiva do que do objecto. Tratase de colocar na agenda da pesquisa em comunicação o estudo específico do processo de socialização. A acção «socializadora», como vimos, não é outra coisa senão a efectiva comunicação da cultura. Num tempo em que se manifestam tantos sinais da ausência ou da deficiência daquele indispensável processo, porque não requerer à pesquisa em comunicação que desenvolva sobre ele novos e actualizados conhecimentos? Para a agenda da investigação em comunicação e cultura toda a realidade social observável se poderia, em princípio, constituir em objecto de estudo. Parece todavia óbvio e consistente que os estudiosos da comunicação desenvolvam tais estudos a partir do extraordinário espelho da 
realidade social que são os média e mais especificamente a grande imprensa de actualidade.

Este desígnio de observação e análise já vem sendo prosseguido entre nós em importantes iniciativas tais como os vários observatórios da comunicação de que temos exemplo em Portugal no OBERCOM, dirigido pelo professor Rui Cádima da Universidade Nova de Lisboa. No mesmo sentido parece colocar-se o projecto de investigação colectiva, MEDIASCÓPIO, coordenado pelo professor Manuel Pinto no Centro de Estudos de Comunicação e Sociedade, na Universidade do Minho. Também a pesquisa realizada sobre La prensa diaria en Galicia (1976-2000), sobre a direcção do professor Xosé López, se orienta em idêntica perspectiva.

A este respeito cabe referir o importante programa de investigação Sueco (Media Panel Program - MPP) sobre os usos dos média, designadamente por parte de crianças e jovens, lançado a partir de 1975 sob a coordenação dos professores E. Rosengren e Sven Windal. Vários estudos resultantes deste programa vêm referidos no livro coordenado por E. Rosengren (1994), já mencionado.

No actual mundo de sociedades abertas e interculturais, em que os fenómenos de anomia e de conflito violento vêm aumentando até níveis de ruptura demasiado frequentes, o processo de socialização ganha maior relevância e urgência. Ele depende em grande medida dos meios e processos de comunicação adequados. Para o seu estudo e promoção poderão e deverão os investigadores da comunicação prestar insubstituível contributo. Não duvido que lhes caiba esta tarefa. Nela cumprirão certamente um desígnio principal e razão maior de ser da sua própria disciplina. 


\section{REFERÊNCIAS BIBLIOGRÁFICAS}

Linton, R. 1973. Cultura e Personalidade (tradução de The Cultural

Background of Personnality, 1945). São Paulo, segunda ed., p. 73.

Rosengren, K. E. 1994. Media Effects and Beyond - Culture, Socialization and Life Styles. Routledge, London.

Rosengren, K. E. 2000. Communication. Sage, London, p. 55.

Touraine, A. 1997. Pourrons-nous vivre ensemble? Fayard, Paris. 